\title{
Epoxide hydrolases: biochemistry and molecular biology
}

\author{
Adrian J. Fretland, Curtis J. Omiecinski * \\ Department of Environmental Health,of Washington, 4225 Roosevelt Way NE, \# 100 Seattle, \\ WA 98105-6099, USA
}

\begin{abstract}
Epoxides are organic three-membered oxygen compounds that arise from oxidative metabolism of endogenous, as well as xenobiotic compounds via chemical and enzymatic oxidation processes, including the cytochrome P450 monooxygenase system. The resultant epoxides are typically unstable in aqueous environments and chemically reactive. In the case of xenobiotics and certain endogenous substances, epoxide intermediates have been implicated as ultimate mutagenic and carcinogenic initiators Adams et al. (Chem. Biol. Interact. 95 (1995) 57-77) Guengrich (Properties and Metabolic roles 4 (1982) 5-30) Sayer et al. (J. Biol. Chem. 260 (1985) 1630-1640). Therefore, it is of vital importance for the biological organism to regulate levels of these reactive species. The epoxide hydrolases (E.C. 3.3.2.3) belong to a sub-category of a broad group of hydrolytic enzymes that include esterases, proteases, dehalogenases, and lipases Beetham et al. (DNA Cell Biol. 14 (1995) 61-71). In particular, the epoxide hydrolases are a class of proteins that catalyze the hydration of chemically reactive epoxides to their corresponding dihydrodiol products. Simple epoxides are hydrated to their corresponding vicinal dihydrodiols, and arene oxides to trans-dihydrodiols. In general, this hydration leads to more stable and less reactive intermediates, however exceptions do exist. In mammalian species, there are at least five epoxide hydrolase forms, microsomal cholesterol 5,6-oxide hydrolase, hepoxilin $\mathrm{A}_{3}$ hydrolase, leukotriene $\mathrm{A}_{4}$ hydrolase, soluble, and microsomal epoxide hydrolase. Each of these enzymes is distinct chemically and immunologically. Table 1 illustrates some general properties for each of these classes of hydrolases. Fig. 1 provides an overview of selected model substrates for each class of epoxide hydrolase. (C) 2000 Elsevier Science Ireland Ltd. All rights reserved.
\end{abstract}

Keywords: Microsomal epoxide hydrolase; Soluble epoxide hydrolase; Cholesterol hydrolase; Hepoxilin $\mathrm{A}_{3}$ hydrolase; Leukotriene hydrolase

* Corresponding author. Tel.: + 1-206-5431700; fax: + 1-206-6854696.

E-mail address: cjo@u.washington.edu (C.J. Omiecinski). 


\section{Cholesterol 5,6-oxide hydrolase}

\subsection{Introduction}

The hydration of cholesterol 5,6 $\alpha$ - and 5,6 $\beta$-oxide (Fig. 1) to cholestane $3 \beta, 5$ $\alpha, 6 \beta$-triol is catalyzed by cholesterol oxide hydrolase, a microsomal hydrolase found in mammalian liver tissues. The gene or cDNA encoding this protein has yet to be cloned or characterized, but is distinct from oxidosqualene cyclase [1]. Cholesterol epoxide hydrolase displays a wide tissue distribution with all tissues tested showing cholesterol epoxide hydrolase activity [2]. Of the tissues tested, liver microsomes have been shown to have the greatest enzymatic activities, five-fold greater than other tissues [2]. In rodents, cholesterol 5,6-oxide hydrolase is inducible by the fibrate drugs such as clofibrate and ciprofibrate [3]. The mechanism of this induction is not understood, but presumably, involves interaction with the peroxisome proliferator-activated receptor $\alpha$.

\subsection{Substrates and inhibitors}

As indicated previously, cholesterol oxide hydrolase is a distinct enzyme from oxidosqualene cyclase, as well as from microsomal epoxide hydrolase, the latter being responsible for the metabolism of a wide range of xenobiotic alkene and arene oxides $[4,1,5]$. Although the cholesterol 5,6 $\beta$-oxide is more reactive than the $\alpha$-oxide upon acid-catalyzed hydration, the $\alpha$-oxide is a 4.5 -fold better substrate than the $\beta$-oxide as indicated by values of $V_{\max } / K_{\mathrm{m}}$ [1]. The enzyme activity of both 5,6 $\alpha$ - and 5,6 $\beta$-oxide diastereomers is product-inhibited by cholestanetriol through a competitive mechanism with the apparent $K_{\mathrm{i}}$ for cholestanetriol being 10.8 and $6.8 \mu \mathrm{M}$ against cholesterol $\alpha$ - and $\beta$-epoxides, respectively [6]. This inhibitory effect of cholestanetriol may account for the difference observed in the hydration rates for the cholesterol epoxide isomers when they are incubated together in the presence of liver microsomes. The parent cholesterol epoxides have been reported to act as weak direct-acting mutagens [7,8]. Although the cholestane-3 $\beta, 5 \alpha, 6 \beta$-triol metabolite was more toxic and a more potent inhibitor of DNA synthesis than the epoxide, it was not significantly mutagenic [7]. Therefore, conditions where conversion rates of the epoxide to the triol are low, as in the case of low-cholesterol epoxide hydrolase activity, appear to favor mutagenicity, whereas rapid conversion to the triol favors cytotoxicity [7].

The rat liver microsomal cholesterol oxide hydrolase is modified and inactivated covalently by the 7-dehydrocholesterol 5,6 $\beta$-oxide [9]. Several imino compounds are competitive inhibitors for the enzyme from rat liver. The most effective of these is 5,6 $\alpha$-iminocholestanol $\left(K_{\mathrm{i}}=0.085 \mu \mathrm{M}\right)$ [1]. Inhibition by aziridines is consistent with the participation of acid catalysis in the mechanism of action of the enzyme [1]. Other inhibitors that have been characterized including the inhibitors 7-ketocholesterol, 6-ketocholestanol, and 7-ketocholestanol, with the latter displaying an apparent $K_{\mathrm{i}}$ lower than the $K_{\mathrm{m}}$ for either cholesterol epoxide isomer. None of the xenobiotic epoxide hydrolase inhibitors or activators studied appears to effect cholesterol-epoxide hydrolase activity $[6,10]$. 

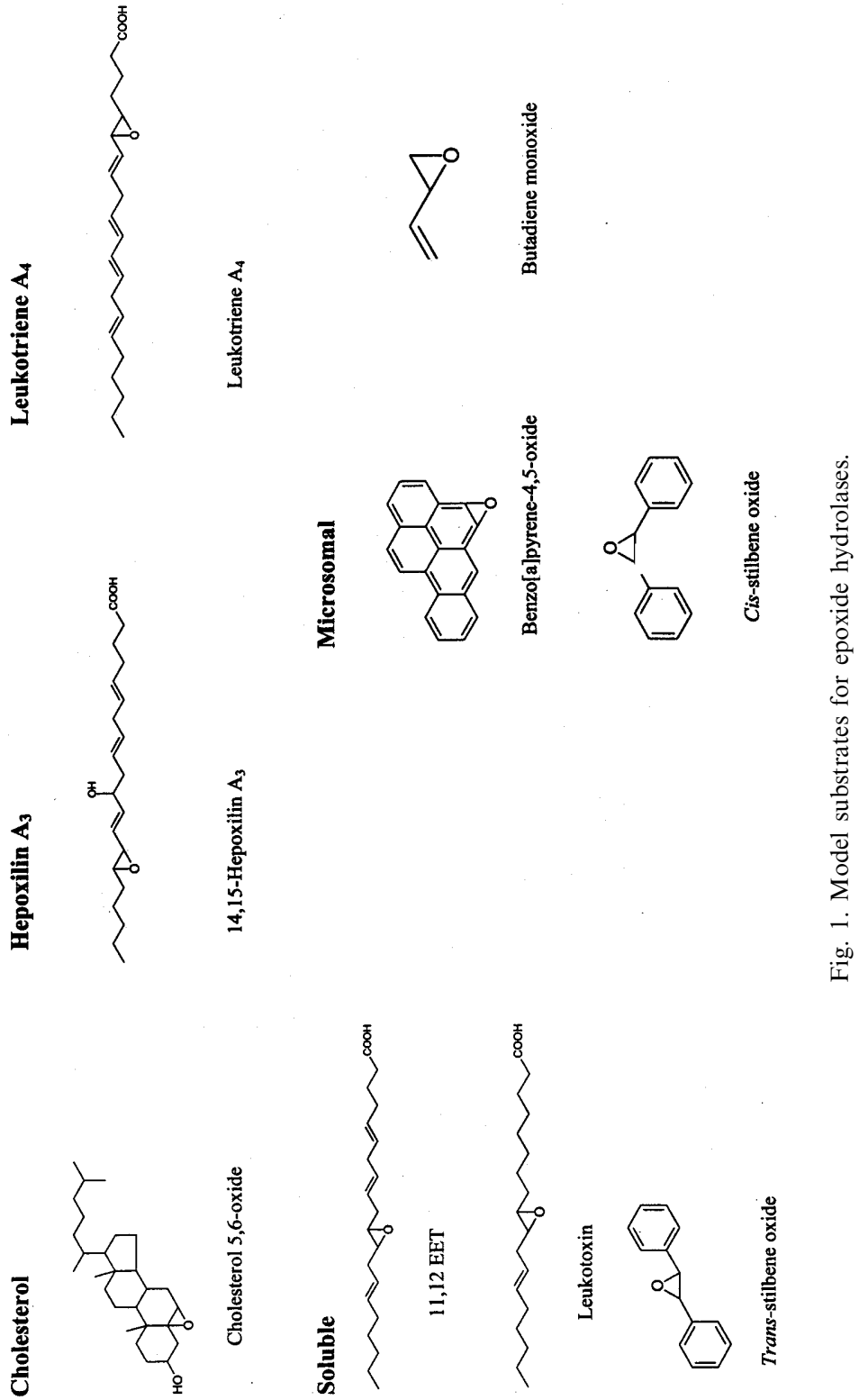
The oxidation of cholesterol proceeds as part of the lipid peroxidation process in membranes. Common oxidation products of lipid peroxide-dependent propagation reactions include the enantiomeric 5,6-epoxides and 7-ketocholestanol [8]. Several of these oxysterol products exhibit cytotoxity, with the cholesterol epoxides demonstrating weakly mutagenic activity [7,8]. Therefore, conversion of cholesterol epoxides to cholestane triol is likely a detoxification function of the hydrolase.

\subsection{Mechanism of action/enzymatic mechanism}

The rat liver microsomal enzyme cholesterol oxide hydrolase is modified and inactivated covalently by the 7-dehydrocholesterol 5,6 $\beta$-oxide, a modification that is likely to occur at the active site of the enzyme since 5,6 $\alpha$-iminocholestanol, a potent competitive inhibitor of the enzyme, blocks incorporation of 3-[3 $\mathrm{H}]$-7-dehydrocholesterol 5,6 $\beta$-oxide into the protein [9]. Unlike xenobiotic microsomal epoxide hydrolase, which is not inactivated or inhibited by 7-dehydrocholesterol 5,6 $\beta$-oxide, cholesterol oxide hydrolase appears to hydrolyze cholesterol oxides via a positively charged transition state [9]. The mammalian soluble and microsomal epoxide hydrolases have been proposed to belong to the family of $\alpha / \beta$-hydrolase-fold enzymes, enzymes that hydrolyze their substrates by a catalytic triad, with the first step of the enzymatic reaction being the formation of a covalent enzyme-substrate ester [5]. Although an enzyme-substrate-ester intermediate is detected in the course of epoxide hydrolysis by microsomal and soluble epoxide hydrolases, no such covalent intermediate between cholesterol epoxide hydrolase and its substrate is detected, indicating that the cholesterol epoxide hydrolase does not, apparently, act by a similar mechanism and is probably not related structurally to microsomal and soluble epoxide hydrolases [5].

\section{Hepoxilin $\mathbf{A}_{3}$ hydrolase}

\subsection{Introduction}

Hepoxilin $\mathrm{A}_{3}$ hydrolase is a cytosolic enzyme that participates in the metabolism of the arachidonic acid metabolites. Like cholesterol 5,6-oxide hydrolase, the gene and/or cDNA for this enzyme have not been cloned or characterized, therefore, knowledge of this epoxide hydrolase is limited to biochemical analyses. The protein responsible for hepoxilin $\mathrm{A}_{3}$ epoxide hydrolase activity has been purified and characterized [11]. Tissue screening indicates that this protein is expressed ubiquitously in mammalian tissues, although its biological roles have been studied principally in tissues of vascular or CNS origin [12-14]. 


\subsection{Substrates and inhibitors}

Hepoxilin epoxide hydrolase activity was first demonstrated in rat liver cytosol using as substrate hepoxilin $\mathrm{A}_{3}$, a hydroxy-epoxide derivative of arachidonic acid [11]. Hepoxilin $A_{3}$ (Fig. 1) is the preferred substrate for the enzyme, converting it to the trihydroxy metabolite trioxilin $\mathrm{A}_{3}$. The enzyme is active only marginally toward other epoxides such as leukotriene $\mathrm{A}_{4}$ and styrene oxide. The $M_{\mathrm{r}}, \mathrm{p} I$, and substrate specificity of hepoxilin epoxide hydrolase indicates that this enzyme is distinct from leukotriene $\mathrm{A}_{4}$ hydrolase [11].

Homogenates of the rat aorta metabolize hepoxilin $A_{3}$ via two competing pathways; one involves hepoxilin epoxide hydrolase to form trioxilin $A_{3}$, and a second pathway involves conjugation of hepoxilin $\mathrm{A}_{3}$ with glutathione via glutathione $S$-transferase to form a glutathione conjugate, hepoxilin $\mathrm{A}_{3}$ [14]. The hepoxilin metabolites likely alter the intracellular concentrations of ions, including calcium and potassium ions, as well dictating alterations in second messenger systems [12]. Recent evidence suggests that the biological actions of the hepoxilins may be receptor-mediated as indicated from data showing the existence of hepoxilin-specific binding proteins in the human neutrophil [15]. Hepoxilin $\mathrm{A}_{3}$ has also been implicated as an endogenous lipid mediator opposing hypotonic swelling of intact human platelets [16]. Trichloropropene oxide (TCPO) has been reported to inhibit effectively the hepoxilin epoxide hydrolase [14,16].

\subsection{Mechanism of action/enzymatic mechanism}

The catalytic mechanisms for hepoxilin hydrolase are largely unknown or unreported. Clearly, this is an area that will require additional study to enable more detailed comparisons of enzymatic mechanism among the various epoxide hydrolases.

\section{Leukotriene $\mathbf{A}_{4}$ hydrolase}

\subsection{Introduction}

Leukotrienes are important arachidonic acid-derived metabolites that mediate inflammatory and allergic response. Leukotriene $\mathrm{A}_{4}$ hydrolase is a bifunctional $\mathrm{Zn}^{2+}$ containing enzyme that exhibits both hydrolase activity, as well as aminopeptidase activity [17]. The human gene for leukotriene $\mathrm{A}_{4}$ hydrolase has been localized to chromosome 12q22, cloned, and characterized [18]. The gene contains 19 exons, spans more than $35 \mathrm{~kb}$, and encodes a protein with an apparent molecular mass of $54 \mathrm{kDa}$ [18]. There have been no reports of genetic variation in leukotriene $\mathrm{A}_{4}$ hydrolase, although there is evidence for alternative mRNA splicing [19]. The alternately spliced form leads to a truncated protein with an altered molecular mass. However, the functional significance of the splice variant in vivo is unknown at this time. The putative promoter region has been cloned and sequenced, as well 
[18]. It contains two xenobiotic response elements (XRE), a phorbol ester response element (AP2), but no definitive TATA box. Upstream of these elements is a consensus sequence for an Alu repeat, which also may regulate gene activity [20]. Leukotriene $\mathrm{A}_{4}$ hydrolase is localized to the cytosolic compartment and its tissue specific expression is ubiquitous [21-23]. The structure, function, and significance of leukotriene $\mathrm{A}_{4}$ hydrolase were reviewed recently [24].

\subsection{Substrates and inhibitors}

Human erythrocytes were shown initially to contain a soluble cytosolic epoxide hydrolase for stereospecific enzymatic hydration of leukotriene $\mathrm{A}_{4}$ (Fig. 1) into leukotriene $\mathrm{B}_{4}$ [22]. The purified enzyme preparation exhibited a molecular weight of $54000 \pm 1000$, an isoelectric point $4.9 \pm 0.2$, an apparent $K_{\mathrm{m}}$ from 7 to $36 \mu \mathrm{M}$ for enzymatic hydration of leukotriene $\mathrm{A}_{4}$, and a $\mathrm{pH}$ optimum ranging from 7 to 8. The enzyme was partially inactivated by its initial exposure to leukotriene $A_{4}$ and catalyzed slow but detectable enzymatic hydration $(\mathrm{pmol} / \mathrm{min} / \mathrm{mg}$ ) of certain arachidonic acid epoxides including $(+/-)$-14,15-oxido-5,8-11-eicosatrienoic acid and (+/-)-11,12-oxido-5,8,14-eicosatrienoic acid, but not others, including 5,6-oxido8,11,14-eicosatrienoic acid. Human erythrocyte leukotriene $\mathrm{A}_{4}$ hydrolase does not catalyze the hydration of either styrene oxide or trans-stilbene oxide [22].

Leukotriene $\mathrm{A}_{4}$ hydrolase is a bifunctional metalloenzyme and contains 1 mol of zinc per mole of protein [24]. The zinc cofactor is necessary for both the enzyme's peptidase and epoxide hydrolase activities. However, at concentrations of zinc $>1: 1$ molar ratio (metal:enzyme), zinc is a an inhibitor with $\mathrm{IC}_{50}$ values of $10 \mu \mathrm{M}$ for the hydrolase activity, i.e. the conversion of leukotriene $A_{4}$ to leukotriene $B_{4}$, and $0.1 \mu \mathrm{M}$ for the peptidase activity [25]. The inhibition of both enzyme activities is reversed by additions of chelating agents such as ethylene diamine tetraacetic acid (EDTA) or dipicolinic acid. Several other divalent cations, in particular $\mathrm{CdSO}_{4}$ and $\mathrm{HgCl}_{2}$, also function to inhibit the hydrolase [25]. The enzyme's peptidase activity is inhibited by $\mathrm{CdSO}_{4}, \mathrm{NiSO}_{4}, \mathrm{HgCl}_{2}, \mathrm{MnCl}_{2}, \mathrm{CoCl}_{2}$, and $\mathrm{PbNO}_{3}$, listed in decreasing order of potency $\left(\mathrm{IC}_{50} 0.5-10 \mathrm{M}\right)$ [25]. In a systematic study on the enzyme specificity and the inhibition of its amidase activity with more than 30 synthetic inhibitors, the identification of specific-keto- $\beta$-animo ester and thioamine inhibitors, as tight-binding, competitive type transition-state analog inhibitors of the aminopeptidase activity, with $K_{\mathrm{i}}$ values of 46 and $18 \mathrm{nM}$, respectively [26,27]. Both compounds inhibited also the epoxide hydrolase activity, with the $\mathrm{IC}_{50}$ values of 1 and $0.1 \mu \mathrm{M}$ for 26 and 27, respectively [26]. Since the enzymatic product, leukotriene $\mathrm{B}_{4}$, is an inflammatory mediator, and leukotriene $\mathrm{A}_{4}$ hydrolase is distributed widely in various cell types and tissues, this activity likely contributes important biological function [28,24].

\subsection{Mechanism of action/enzymatic mechanism}

From sequence comparisons with aminopeptidases, a tyrosine at position 383 in leukotriene $\mathrm{A}_{4}$ hydrolase identified as a possible catalytic residue and tested in this 
respect using site-specific mutagenesis to substitute this position with phenylalanine, histidine or glutamine [29]. The mutated proteins exhibited peptidase activities $<0.3 \%$ that of the wild-type enzyme. However, the epoxide hydrolase function was not impacted to the same degree, corresponding to 11,16 and $17 \%$ that of the wild-type enzyme for the $\mathrm{Tyr}^{383} \mathrm{Phe}, \mathrm{Tyr}^{383} \mathrm{His}$ and $\mathrm{Tyr}^{383} \mathrm{Glu}$ leukotriene $\mathrm{A}_{4}$ hydrolases, respectively. The results from this study are consistent with a role for $\mathrm{Tyr}^{383}$ in the peptidase reaction of leukotriene $\mathrm{A}_{4}$ hydrolase, where it may act as a proton donor in a general base mechanism. These and other data provide evidence that the two catalytic activities of leukotriene $\mathrm{A}_{4}$ hydrolase involve non-identical but overlapping active sites [29,30]. Evidence for a carbocation intermediate has been reported in the enzymatic transformation of leukotriene $A_{4}$ into leukotriene $B_{4}$ [31]. Based on sequence alignment studies, leukotriene $A_{4}$ hydrolase is likely not related to the other epoxide hydrolases, in particular soluble and microsomal epoxide hydrolase, and does not share a common enzymatic mechanism [32].

\section{Soluble epoxide hydrolase}

\subsection{Introduction}

Soluble epoxide hydrolase (or cytosolic epoxide hydrolase) is a xenobiotic metabolizing enzyme that also participates in the metabolism of endogenously derived fatty acid epoxides [33]. The protein responsible for soluble epoxide hydrolase (sEH) activity has been purified and characterized [34-37]. sEH activity is apparently expressed in all tissues [38]. Purified sEH protein from mammalian species possesses an imperfect peroxisomal targeting sequencing aT at the C-terminus $[36,37,39]$. Although the majority of the enzymatic activity is observed in the cytosolic fraction, activity in the peroxisomal fraction also has been detected [38-40]. The gene and/or cDNAs of sEH from a variety of different species have been cloned and characterized [36,41-44]. The human gene is localized to chromosome 8p21-p12, spans approximately $45 \mathrm{~kb}$, and consists of 19 exons, with the first exon being non-coding [43].

Variation in sEH has been observed in human populations. Past investigations have demonstrated an 11-fold variation in sEH activity in unstimulated lymphocytes [45]. Results of twin and family studies examining sEH activities suggest predominantly genetic control with either monogenic or polygenic control mechanisms [45]. Further studies have indicated the presence of genetic polymorphism at the sEH gene locus [46]. Rodent species exhibit an induction of sEH activity when treated with peroxisomal proliferator agents, such as 2,4-dichlorophenoyacetic acid and Wyeth 14.643, and hypolipidemic drugs, such as clofibrate [47-51]. The mechanism of this induction has not been investigated, but involves likely the peroxisomal proliferator-activated receptor $\alpha$ pathway. There has been no reported induction of $\mathrm{sEH}$ in human populations. 


\subsection{Substrates and inhibitors}

$\mathrm{sEH}$ in general catalyzes the hydrolysis of trans-substituted epoxides, as well as various aliphatic epoxides derived from fatty acid metabolism [33,52]. The prototypic substrate used to distinguish $\mathrm{sEH}$ activity from microsomal epoxide hydrolase activity is trans-stilbene oxide (Fig. 1) [51]. Other more sensitive radiometric substrates have been developed for sEH [53]. These include $\left[{ }^{14} \mathrm{C}\right] \mathrm{cis}-9,10$-epoxystearic acid and $\left[2-{ }^{3} \mathrm{H}\right]$ trans-1,3-diphenyl-propene oxide. The latter substrates provide a higher sensitivity with increased maximal velocities when compared with trans-stilbene oxide. Several additional specific sEH substrates have been developed and characterized [54], including a series of epoxy esters and carbonate-derivatives that cyclize spontaneously upon hydrolysis of the epoxide, releasing an alcohol. These substrates, therefore, enable rapid spectrophotometric analysis of sEH activity without the use of radiolabeled probes. Numerous investigations have demonstrated the importance of sEH in the metabolism of diepoxy fatty methylesters and epoxyeicosatrienoic acids (EETs) [52,55,56]. Recently, sEH was shown to bioactivate leukotoxin (Fig. 1), a linoleic acid metabolite [57]. These latter substances represent endogenous metabolic products of fatty acid metabolism and implicate a potentially important role for $\mathrm{sEH}$ in mediating pathophysiologic and physiologic processes.

Several classes of sEH inhibitors have been developed. Early work characterized chalcone oxide derivatives as inhibitors of sEH [58]. Later studies characterized trans-3-phenylglycidols as inhibitors of rodent, monkey and human sEH, but not microsomal epoxide hydrolase [59,60]. More recently, potent competitive inhibitors of sEH based on urea and carbamates have been characterized. The most potent of these inhibitors have $K_{\mathrm{I}} \mathrm{s}$ in the nanomolar range [61]. The heavy metals $\mathrm{Cd}^{2+}$ and $\mathrm{Cu}^{2+}$ have been identified as competitive inhibitors of $\mathrm{sEH}$, and may represent a mechanism of $\mathrm{sEH}$ regulation during inflammation [62].

The importance of sEH in normal metabolism of endogenous metabolites of fatty acids is well established. Leukotoxin is bioactivated via sEH metabolism [57]. Leukotoxin is an oxidative metabolite of linoleic acid in leukocytes, that has been associated with multiple organ failure and adult respiratory distress syndrome seen in some severe burn patients. Epoxyeicosatrienoic acids (EETs) are P450 derived metabolites of arachidonic acid that possess a multitude of biologic activities. These include activation of $\mathrm{Ca}^{2+}$-activated $\mathrm{K}^{+}\left(K_{\mathrm{ca}}\right)$ channels inducing a potent relaxation of blood vessels, thereby implicating EETs as candidates for endotheliumderived hyperpolarization factors (EDHF) in coronary blood vessels [63,64]. sEH has been shown to regulate EET incorporation into phospholipids [65], suggestive of sEH modulation of endothelial function via activation of $K_{\mathrm{ca}}$ channels.

\subsection{Mechanism of action/enzymatic mechanism}

Of the known epoxide hydrolases, sEH is associated likely with the most in depth characterization with respect to enzymatic mechanism and structure. This information has been forthcoming from numerous sequence comparisons, biochemical, and 
crystallographic investigations. Based on sequence alignment analyses, it was concluded that sEH belongs to a broad group of $\alpha / \beta$ hydrolase enzymes that include bacterial haloalkane dehalogenase $[32,66]$. The alignment characterization also lead to identification of a proposed catalytic triad of amino acids within sEH. Mutagenesis experiments implicated $\mathrm{Asp}^{333}$ and $\mathrm{His}^{523}$ in the catalytic mechanism for $\mathrm{sEH}$, similar to other $\alpha / \beta$ hydrolase enzymes [67]. The results of the latter investigation indicated that since $\mathrm{His}^{523}$ was conserved in all epoxide hydrolase across species, and mutation of $\mathrm{His}^{523}$ in murine $\mathrm{sEH}$ resulted in activity of $0.1 \%$ of wild-type activity, this residue was likely a key participant in the catalytic mechanism for the hydrolase. Further biochemical analyses revealed the formation of an $\alpha$-hydroxyacyl-enzyme intermediate initiated by amino acid $\operatorname{Asp}^{333}$ [68]. This intermediate was hydrolyzed by the addition of water to the carbonyl carbon of the ester bond, yielding the dihydrodiol product. Other data also supported the role of $\mathrm{Asp}^{333}$ and $\mathrm{His}^{523}$ in the catalytic mechanism, and implicated further the participation of the $\mathrm{Asp}^{495}$ residue [69]. Results from the latter study, along with others, suggest a nucleophilic attack of the oxirane ring by $\mathrm{Asp}^{333}$ leading to the formation of the $\alpha$-hydroxyacyl-enzyme intermediate shown by Borhan et al. [68]. The $\mathrm{His}^{523}-\mathrm{Asp}^{495}$ pair creates an environment that abstracts a proton from a water molecule, thereby activating it and hydrolyzing the $\alpha$-hydroxyacyl-enzyme intermediate, yielding the dihydrodiol product. The crystal structure of recombinant murine sEH was elucidated in 1999 by Argiriadi et al. [70]. The results of the crystal data confirmed previous enzymological investigations that led to the identification of the catalytic triad of sEH. Interestingly, the crystal analysis demonstrated a vestigial active site in the N-terminal domain of $\mathrm{sEH}$ and its similarity to the active site in bacterial haloacid dehalogenase. In $\mathrm{sEH}$, this vestigial site does not participate in epoxide hydrolysis, but does play an important role in the stabilization of the dimeric structure of $\mathrm{sEH}$.

\section{Microsomal epoxide hydrolase}

\subsection{Introduction}

Of the known epoxide hydrolases, microsomal epoxide hydrolase (mEH) was the first characterized. $\mathrm{mEH}$ catalyzes the trans-addition of water to a broad range of epoxide substrates. There has been great interest in $\mathrm{mEH}$ because of its potential involvement in the bioactivation of carcinogenic polycyclic aromatic hydrocarbons [71]. However, mEH does play an important role in the detoxification of many reactive epoxide intermediates [72,73]. There appears to be universal expression of $\mathrm{mEH}$ in all tissues studied to date [72,74]. The highly conserved protein catalyzing $\mathrm{mEH}$ activity has been purified and the protein sequence determined in several mammalian species [32,75-78]. The gene and cDNA for $\mathrm{mEH}$ has been cloned, sequenced in humans $[77,79]$. The gene exists as a single copy in the haploid genome and has been localized to the long arm of chromosome 1 [77]. The gene encompasses approximately $20 \mathrm{~kb}$ and is comprised of eight coding exons, one non-coding 
exon, and encodes for a single monomeric protein of 455 amino acids. The 5 -flanking region of $\mathrm{mEH}$ has been cloned and characterized [80], and human $\mathrm{mEH}$ expression levels appear to be effected only modestly by exposures to common chemical inducers in primary hepatocyte culture [81]. However, in rodent species, $\mathrm{mEH}$ appears to be highly inducible by a number of prototypic chemicals [82-85]. In vitro transfection studies using promoter constructs have indicated a repression of epoxide hydrolase driven chloramphenicol $O$-acetyltransferase (CAT) activity and epoxide hydrolase mRNA by dexamethasone [86].

There exist certain well-characterized genetic polymorphisms in human $\mathrm{mEH}$ $[87,88]$. The coding region of $\mathrm{mEH}$ presents with two prominent genetic polymorphisms. The first, within exon 3, results in the substitution of Tyr with His at amino acid position 113; another, within exon 4, codes for the substitution of a His with Arg at amino acid position 139. In transiently transfected cells, using benzo[a]pyrene-4,5-oxide as substrate probe, the $\mathrm{Tyr}^{113} / \mathrm{Arg}^{139}$ variant exhibited approximately 2 -fold higher levels of enzymatic activity than the $\mathrm{His}^{113} / \mathrm{His}^{139}$ variant when normalized to total $\mathrm{S} 9$ protein or $\mathrm{mEH}$ mRNA of the transfected cell extracts [88]. However, when results were normalized to $\mathrm{mEH}$ immunodetectable protein levels, the variants appeared to encode only marginal phenotypic differences. These data, together with results from additional studies [89,90], suggest that differences in protein stability among the variant $\mathrm{mEH}$ proteins may factor into the basis of observed interindividual differences in $\mathrm{mEH}$ phenotype. Additionally, seven other 5'-flanking region genetic polymorphisms have been described [91], and may also impact $\mathrm{mEH}$ gene transcriptional activity and resulting cellular phenotype.

\subsection{Substrates and inhibitors}

In contrast to sEH and other epoxide hydrolases, the major role of $\mathrm{mEH}$ is likely oriented toward the metabolism of xenobiotic compounds. The substrates of $\mathrm{mEH}$ are generally quite specific to this hydrolase, with little or no activity exhibited towards the other epoxide hydrolases. Typical substrates include toxic and procarcinogenic compounds, as well as commonly used anticonvulsant drugs. The most common environmental compound metabolized by $\mathrm{mEH}$ are epoxide derivatives of polycyclic aromatic hydrocarbons (Table 1, benzo[a]pyrene 4,5-oxide). The dihydrodiol products of $\mathrm{mEH}$ metabolism have been implicated as ultimate reactive carcinogens that are responsible for polycyclic aromatic hydrocarbon-initiated carcinogenesis. Other xenobiotic compounds of note that are metabolized by $\mathrm{mEH}$ are the epoxide derivatives of 1,3-butadiene (Table 1) [92-94], benzene [95,96], aflatoxin $B_{1}$ [97-99], chrysene [100,101], nitropyrene [102], naphthalene, and anthracene $[103,104]$. The importance of $\mathrm{mEH}$ is underscored by data obtained from a mEH knockout mouse model that show reduced carcinogenicity of 7,12-dimethylbenz[a]anthracene in knockout versus control animals [105]. The most commonly used probe substrates for $\mathrm{mEH}$ activity are cis-stilbene oxide [106-108] and styrene oxide [109-111]. The former is commonly used to differentiate between microsomal and soluble epoxide hydrolase activity. Important clinical drugs metabolized by $\mathrm{mEH}$ include epoxide derivatives of anticonvulsant drugs, phenytoin [112-114] and 


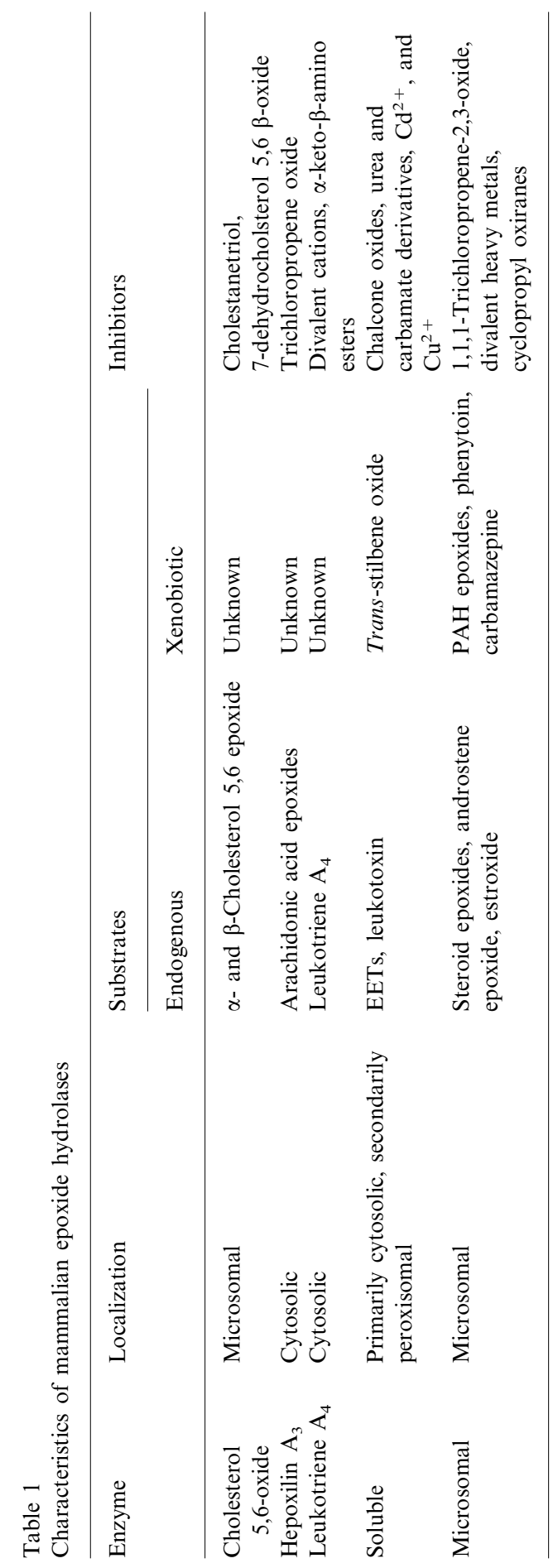


carbamazepine [115,116]. $\mathrm{mEH}$ has been hypothesized to play a role in the endogenous metabolism of estroxide and androstene oxide [117].

Inhibitors of microsomal epoxide hydrolase have been developed and characterized. Early studies identified 1,1,1-trichloropropene-2,3-oxide as an inhibitor of both rodent and human $\mathrm{mEH}$ [118]. Later studies demonstrated that the cyclopropyl oxiranes were competitive reversible inhibitors of $\mathrm{mEH}$, with some having equal $\mathrm{IC}_{50}$ of 1,1,1-trichloropropene-2,3-oxide [119]. Recently, divalent heavy metals were shown to inhibit $\mathrm{mEH}$ enzymatic activity [62]. The most potent of the inhibitors was $\mathrm{Zn}^{2+}$ and $\mathrm{Hg}^{2+}$ with $\mathrm{IC}_{50}$ s of approximately $20 \mu \mathrm{M}$.

$\mathrm{mEH}$ plays an important role in the metabolism of many xenobiotic compounds, including common toxicants and clinical drugs. Common anticonvulsant drugs (i.e. phenytoin, carbamazepine, etc.) are associated with a potentially lethal hypersensitivity syndrome, with symptoms that include fever, rash, lymphadenopathy, and hepatitis [120]. Since mEH does metabolize these compounds and is known to be polymorphic in human populations, it may be responsible for the idiosyncratic hypersensitiviy syndrome. In fact, Shear et al. have reported an association of an inherited defect in microsomal epoxide hydrolase activity with drug toxicity [121]. However, more recent investigations have not confirmed these associations [87,122]. Other predisposing factors in these reactions may relate to high levels of circulating autoantibodies to P450, suggesting an immunologic disease mechanism [123]. Polymorphisms in $\mathrm{mEH}$ too may lead to differences in host-mediated bioactivation of procarcinogens resulting in differential susceptibility to cancers of various tissues. Numerous human epidemiological studies have examined the role of the polymorphism in $\mathrm{mEH}$ and tumor formation [124-128]. These data suggest that $\mathrm{mEH}$ genotype is associated with altered risk of several types of cancers and pulmonary disease.

\subsection{Mechanism of action/enzymatic mechanism}

Although a crystal structure for $\mathrm{mEH}$ has not been produced, there is a good understanding of its enzymatic mechanism. Like sEH, $\mathrm{mEH}$ is a member of the $\alpha / \beta$-hydrolase enzyme family [66]. Based on its similarity with bacterial haloalkane dehalogenases and other epoxide hydrolases, a catalytic triad consisting of a His ${ }^{431}$, $\mathrm{Asp}^{226}$, and a Glu ${ }^{404}$ has been proposed [129,130]. These findings are based on earlier reports of a His at position 431 that is essential for catalysis [131], and sequence alignments of related epoxide hydrolases. The mechanism of $\mathrm{mEH}$ generally follows a mechanism similar to that of $\mathrm{sEH}$, with the attack of the oxirane ring to yield an alkyl-enzyme intermediate followed by subsequent hydrolysis of the intermediate by water [132]. An interesting finding is the similarity of sEH from Aspergillus niger (A. niger) to mammalian $\mathrm{mEH}$ [133]. The protein from this species shares a similar catalytic triad to mammalian species and is also a member of the $\alpha / \beta$-hydrolase enzymes. Recently, the crystal structure for epoxide hydrolase from $A$. niger was elucidated [134]. The findings of this report indicate that due to the narrow hydrophobic tunnel of the active site, $\mathrm{mEH}$ is unable to catalyze the hydrolysis of bulky trans-substituted epoxides. It also suggests a role for residues 
$320-328$ in the interaction of $\mathrm{mEH}$ with other proteins, possibly epoxide-generating proteins such as the cytochrome P450s.

\section{Acknowledgements}

The authors acknowledge gratefully the support of the Burroughs Wellcome Fund and the National Institute of Environmental Health Sciences (ES04978, ES07033).

\section{References}

[1] N.T. Nashed, D.P. Michaud, W. Levin, D.M. Jerina, Properties of liver microsomal cholesterol 5,6-oxide hydrolase, Arch. Biochem. Biophys. 241 (1985) 149-162.

[2] A. Astrom, M. Eriksson, L.C. Eriksson, W. Birberg, A. Pilotti, J.W. DePierre, Subcellular and organ distribution of cholesterol epoxide hydrolase in the rat, Biochim. Biophys. Acta 882 (1986) 359-366.

[3] B.L. Finley, B.D. Hammock, Increased cholesterol epoxide hydrolase activity in clofibrate-fed animals, Biochem. Pharmacol. 37 (1988) 3169-3175.

[4] W. Levin, D.P. Michaud, P.E. Thomas, D.M. Jerina, Distinct rat hepatic microsomal epoxide hydrolases catalyze the hydration of cholesterol 5,6 $\alpha$-oxide and certain xenobiotic alkene and arene oxides, Arch. Biochem. Biophys. 220 (1983) 485-494.

[5] F. Muller, M. Arand, H. Frank, A. Seidel, W. Hinz, L. Winkler, K. Hanel, J.K. Beetham, B.D. Hammock, F. Oesch, Visualization of a covalent intermediate between microsomal epoxide hydrolase, but not cholesterol epoxide hydrolase, and their substrates, Eur. J. Biochem. 245 (1997) 490-496.

[6] A. Sevanian, L.L. McLeod, Catalytic properties and inhibition of hepatic cholesterol-epoxide hydrolase, J. Biol. Chem. 261 (1986) 54-59.

[7] A. Sevanian, A.R. Peterson, Cholesterol epoxide is a direct-acting mutagen, Proc. Natl. Acad. Sci. USA 81 (1984) 4198-4202.

[8] A. Sevanian, A.R. Peterson, The cytotoxic and mutagenic properties of cholesterol oxidation products, Food Chem. Toxicol. 24 (1986) 1103-1110.

[9] N.T. Nashed, D.P. Michaud, W. Levin, D.M. Jerina, 7-Dehydrocholesterol 5,6 $\alpha$-oxide as a mechanism-based inhibitor of microsomal cholesterol oxide hydrolase, J. Biol. Chem. 261 (1986) $2510-2513$.

[10] T. Watabe, T. Komatsu, M. Isobe, A. Tsubaki, Mouse liver microsomal cholesterol epoxide hydrolase: a specific inhibition of its activity by 5,6 $\alpha$-imino- $5 \alpha$-cholestan-3 $\alpha$-OL, Chem. Biol. Interact. 44 (1983) 143-154.

[11] C.R. Pace-Asciak, W.S. Lee, Purification of hepoxilin epoxide hydrolase from rat liver, J. Biol Chem. 264 (1989) 9310-9313.

[12] C.R. Pace-Asciak, Hepoxilins: a review on their cellular actions, Biochim. Biophys. Acta 1215 (1994) $1-8$.

[13] D. Reynaud, P. Demin, C.R. Pace-Asciak, Hepoxilin $A_{3}$ formation in the rat pineal gland selectively utilizes (12S)-hydroperoxyeicosatetraenoic acid (HPETE), but not (12R)-HPETE, J. Biol. Chem. 269 (1994) 23976-23980.

[14] O. Laneuville, E.J. Corey, R. Couture, C.R. Pace-Asciak, Hepoxilin $\mathrm{A}_{3}$ (HxA3) is formed by the rat aorta and is metabolized into HxA3-C, a glutathione conjugate, Biochim. Biophys. Acta 1084 (1991) 60-68.

[15] D. Reynaud, P.M. Demin, M. Sutherland, S. Nigam, C.R. Pace-Asciak, Hepoxilin signaling in intact human neutrophils: biphasic elevation of intracellular calcium by unesterified hepoxilin $\mathrm{A}_{3}$, FEBS Lett. 446 (1999) 236-238. 
[16] A. Margalit, Y. Sofer, S. Grossman, D. Reynaud, C.R. Pace-Asciak, A.A. Livne, Hepoxilin $A_{3}$ is the endogenous lipid mediator opposing hypotonic swelling of intact human platelets, Proc. Natl. Acad. Sci. USA 90 (1993) 2589-2592.

[17] J.Z. Haeggstrom, A. Wetterholm, J.F. Medina, B. Samuelsson, Novel structural and functional properties of leukotriene $\mathrm{A}_{4}$ hydrolase. Implications for the development of enzyme inhibitors, Adv. Prostaglandin Thromb. Leukot. Res. 22 (1994) 3-12.

[18] J.A. Mancini, J.F. Evans, Cloning and characterization of the human leukotriene $\mathrm{A}_{4}$ hydrolase gene, Eur. J. Biochem. 231 (1995) 65-71.

[19] E. Jendraschak, W.E. Kaminski, R. Kiefl, S.C. von, The human leukotriene $\mathrm{A}_{4}$ hydrolase gene is expressed in two alternatively spliced mRNA forms, Biochem. J. 314 (1996) 733-737.

[20] E. Jendraschak, W.E. Kaminski, Isolation of human promoter regions by Alu repeat consensusbased polymerase chain reaction, Genomics 50 (1998) 53-60.

[21] J.Y. Fu, J. Haeggstrom, P. Collins, J. Meijer, O. Radmark, Leukotriene A hydrolase: analysis of some human tissues by radioimmunoassay, Biochim. Biophys. Acta 1006 (1989) 121-126.

[22] J. McGee, F. Fitzpatrick, Enzymatic hydration of leukotriene A . Purification and characterization of a novel epoxide hydrolase from human erythrocytes, J. Biol. Chem. 260 (1985) 12832-12837.

[23] I.V. Rybina, H. Liu, Y. Gor, S.J. Feinmark, Regulation of leukotriene $A_{4}$ hydrolase activity in endothelial cells by phosphorylation, J. Biol. Chem. 272 (1997) 31865-31871.

[24] J.Z. Haeggstrom, Structure, function, and regulation of leukotriene $\mathrm{A}_{4}$ hydrolase, Am. J. Respir. Crit. Care Med. 161 (2000) S25-S31.

[25] A. Wetterholm, L. Macchia, J.Z. Haeggstrom, Zinc and other divalent cations inhibit purified leukotriene $\mathrm{A}_{4}$ hydrolase and leukotriene $\mathrm{B}_{4}$ biosynthesis in human polymorphonuclear leukocytes, Arch. Biochem. Biophys. 311 (1994) 263-271.

[26] W. Yuan, B. Munoz, C.H. Wong, J.Z. Haeggstrom, A. Wetterholm, B. Samuelsson, Development of selective tight-binding inhibitors of leukotriene $A_{4}$ hydrolase, J. Med. Chem. 36 (1993) 211-220.

[27] M. Andberg, A. Wetterholm, J.F. Medina, J.Z. Haeggstrom, Leukotriene $A_{4}$ hydrolase: a critical role of glutamic acid-296 for the binding of bestatin, Biochem. J. 345 (2000) 621-625.

[28] G.M. Habib, A.A. Cuevas, R. Barrios, M.W. Lieberman, Mouse leukotriene $\mathrm{A}_{4}$ hydrolase is expressed at high levels in intestinal crypt cells and splenic lymphocytes, Gene 234 (1999) 249-255.

[29] M. Blomster, A. Wetterholm, M.J. Mueller, J.Z. Haeggstrom, Evidence for a catalytic role of tyrosine 383 in the peptidase reaction of leukotriene $\mathrm{A}_{4}$ hydrolase, Eur. J. Biochem. 231 (1995) 528-534.

[30] J.Z. Haeggstrom, A. Wetterholm, J.F. Medina, B. Samuelsson, Leukotriene $\mathrm{A}_{4}$ hydrolase: structural and functional properties of the active center, J. Lipid Mediat. 6 (1993) 1-13.

[31] M. Andberg, M. Hamberg, J.Z. Haeggstrom, Evidence for a carbocation intermediate in the enzymatic transformation of leukotriene $\mathrm{A}_{4}$ into leukotriene $\mathrm{B}_{4}$, Adv. Exp. Med. Biol. 469 (1999) 319-325.

[32] J.K. Beetham, D. Grant, M. Arand, J. Garbarino, T. Kiyosue, F. Pinot, F. Oesch, W.R. Belknap, K. Shinozaki, B.D. Hammock, Gene evolution of epoxide hydrolases and recommended nomenclature, DNA Cell Biol. 14 (1995) 61-71.

[33] J. Meijer, J.W. DePierre, Cytosolic epoxide hydrolase, Chem. Biol. Interact. 64 (1988) 207-249.

[34] L. Schladt, R. Hartmann, W. Worner, H. Thomas, F. Oesch, Purification and characterization of rat-liver cytosolic epoxide hydrolase, Eur. J. Biochem. 176 (1988) 31-37.

[35] L. Schladt, H. Thomas, R. Hartmann, F. Oesch, Human liver cytosolic epoxide hydrolases, Eur. J. Biochem. 176 (1988) 715-723.

[36] J.K. Beetham, T. Tian, B.D. Hammock, cDNA cloning and expression of a soluble epoxide hydrolase from human liver, Arch. Biochem. Biophys. 305 (1993) 197-201.

[37] H. Thomas, L. Schladt, J. Doehmer, M. Knehr, F. Oesch, Rat and human liver cytosolic epoxide hydrolases: evidence for multiple forms at level of protein and mRNA, Environ. Health Perspect. 88 (1990) 49-55.

[38] L. Schladt, W. Worner, F. Setiabudi, F. Oesch, Distribution and inducibility of cytosolic epoxide hydrolase in male Sprague-Dawley rats, Biochem. Pharmacol. 35 (1986) 3309-3316.

[39] M. Arand, M. Knehr, H. Thomas, H.D. Zeller, F. Oesch, An impaired peroxisomal targeting sequence leading to an unusual bicompartmental distribution of cytosolic epoxide hydrolase, FEBS Lett. 294 (1991) 19-22. 
[40] A.M. Eriksson, M.A. Zetterqvist, B. Lundgren, K. Andersson, B. Beije, J.W. DePierre, Studies on the intracellular distributions of soluble epoxide hydrolase and of catalase by digitonin-permeabilization of hepatocytes isolated from control and clofibrate-treated mice, Eur. J. Biochem. 198 (1991) $471-476$

[41] D.F. Grant, D.H. Storms, B.D. Hammock, Molecular cloning and expression of murine liver soluble epoxide hydrolase, J. Biol. Chem. 268 (1993) 17628-17633.

[42] M. Knehr, H. Thomas, M. Arand, T. Gebel, H.D. Zeller, F. Oesch, Isolation and characterization of a cDNA encoding rat liver cytosolic epoxide hydrolase and its functional expression in Escherichia coli, J. Biol. Chem. 268 (1993) 17623-17627.

[43] M. Sandberg, J. Meijer, Structural characterization of the human soluble epoxide hydrolase gene (EPHX2), Biochem. Biophys. Res. Commun. 221 (1996) 333-339.

[44] A. Stapleton, J.K. Beetham, F. Pinot, J.E. Garbarino, D.R. Rockhold, M. Friedman, B.D. Hammock, W.R. Belknap, Cloning and expression of soluble epoxide hydrolase from potato, Plant J. 6 (1994) 251-258.

[45] E.S. Vesell, Genetic factors that regulate cytosolic epoxide hydrolase activity in normal human lymphocytes, Ann. Genet. 34 (1991) 167-172.

[46] M. Sandberg, C. Hassett, J. Meijer, E.T. Adman, C.J. Omiecinski, Identification and functional characterization of human soluble epoxide hydrolase genetic polymorphisms, J. Biol. Chem. 275 (2000) 28873-28881.

[47] C. Johansson, A. Stark, M. Sandberg, B. Ek, L. Rask, J. Meijer, Tissue specific basal expression of soluble murine epoxide hydrolase and effects of clofibrate on the mRNA levels in extrahepatic tissues and liver, Arch. Toxicol. 70 (1995) 61-63.

[48] B. Lundgren, J. Meijer, J.W. DePierre, Induction of cytosolic and microsomal epoxide hydrolases and proliferation of peroxisomes and mitochondria in mouse liver after dietary exposure to p-chlorophenoxyacetic acid, 2,4-dichlorophenoxyacetic acid and 2,4,5-trichlorophenoxyacetic acid, Biochem. Pharmacol. 36 (1987) 815-821.

[49] B. Lundgren, J. Meijer, W. Birberg, A. Pilotti, J.W. DePierre, Induction of cytosolic and microsomal epoxide hydrolases in mouse liver by peroxisome proliferators, with special emphasis on structural analogues of 2-ethylhexanoic acid, Chem. Biol. Interact. 68 (1988) 219-240.

[50] B. Lundgren, J.W. DePierre, Proliferation of peroxisomes and induction of cytosolic and microsomal epoxide hydrolases in different strains of mice and rats after dietary treatment with clofibrate, Xenobiotica 19 (1989) 867-881.

[51] F. Oesch, L. Schladt, R. Hartmann, C. Timms, W. Worner, Rat cytosolic epoxide hydrolase, Adv. Exp. Med. Biol. 197 (1986) 195-201.

[52] D.C. Zeldin, S. Wei, J.R. Falck, B.D. Hammock, J.R. Snapper, J.H. Capdevila, Metabolism of epoxyeicosatrienoic acids by cytosolic epoxide hydrolase: substrate structural determinants of asymmetric catalysis, Arch. Biochem. Biophys. 316 (1995) 443-451.

[53] B. Borhan, T. Mebrahtu, S. Nazarian, M.J. Kurth, B.D. Hammock, Improved radiolabeled substrates for soluble epoxide hydrolase, Anal. Biochem. 231 (1995) 188-200.

[54] E.C. Dietze, E. Kuwano, B.D. Hammock, Spectrophotometric substrates for cytosolic epoxide hydrolase, Anal. Biochem. 216 (1994) 176-187.

[55] J. Nourooz Zadeh, T. Uematsu, B. Borhan, M.J. Kurth, B.D. Hammock, Characterization of the cytosolic epoxide hydrolase-catalyzed hydration products from 9,10:12,13-diepoxy stearic esters, Arch. Biochem. Biophys. 294 (1992) 675-685.

[56] D.C. Zeldin, J. Kobayashi, J.R. Falck, B.S. Winder, B.D. Hammock, J.R. Snapper, J.H. Capdevila, Regio- and enantiofacial selectivity of epoxyeicosatrienoic acid hydration by cytosolic epoxide hydrolase, J. Biol. Chem. 268 (1993) 6402-6407.

[57] M.F. Moghaddam, D.F. Grant, J.M. Cheek, J.F. Greene, K.C. Williamson, B.D. Hammock, Bioactivation of leukotoxins to their toxic diols by epoxide hydrolase, Nat. Med. 3 (1997) $562-566$.

[58] T. Miyamoto, M. Silva, B.D. Hammock, Inhibition of epoxide hydrolases and glutathione $S$-transferases by 2-, 3-, and 4-substituted derivatives of 4'-phenylchalcone and its oxide, Arch. Biochem. Biophys. 254 (1987) 203-213. 
[59] E.C. Dietze, E. Kuwano, J. Casas, B.D. Hammock, Inhibition of cytosolic epoxide hydrolase by trans-3-phenylglycidols, Biochem. Pharmacol. 42 (1991) 1163-1175.

[60] E.C. Dietze, J. Casas, E. Kuwano, B.D. Hammock, Inhibition of epoxide hydrolase from human, monkey, bovine, rabbit and murine liver by trans-3-phenylglycidols, Comp. Biochem. Physiol. B 104 (1993) 309-314.

[61] C. Morisseau, M.H. Goodrow, D. Dowdy, J. Zheng, J.F. Greene, J.R. Sanborn, B.D. Hammock, Potent urea and carbamate inhibitors of soluble epoxide hydrolases, Proc. Natl. Acad. Sci. USA 96 (1999) 8849-8854.

[62] A.J. Draper, B.D. Hammock, Inhibition of soluble and microsomal epoxide hydrolase by zinc and other metals, Toxicol. Sci. 52 (1999) 26-32.

[63] B. Fisslthaler, R. Popp, L. Kiss, M. Potente, D.R. Harder, I. Fleming, R. Busse, Cytochrome P450 2C is an EDHF synthase in coronary arteries, Nature 401 (1999) 493-497.

[64] B. Fisslthaler, I. Fleming, R. Busse, EDHF: a cytochrome P450 metabolite in coronary arteries, Semin. Perinatol. 24 (2000) 15-19.

[65] N.L. Weintraub, X. Fang, T.L. Kaduce, M. VanRollins, P. Chatterjee, A.A. Spector, Epoxide hydrolases regulate epoxyeicosatrienoic acid incorporation into coronary endothelial phospholipids, Am. J. Physiol. 277 (1999) H2098-H2108.

[66] M. Arand, D.F. Grant, J.K. Beetham, T. Friedberg, F. Oesch, B.D. Hammock, Sequence similarity of mammalian epoxide hydrolases to the bacterial haloalkane dehalogenase and other related proteins. Implication for the potential catalytic mechanism of enzymatic epoxide hydrolysis, FEBS Lett. 338 (1994) 251-256.

[67] F. Pinot, D.F. Grant, J.K. Beetham, A.G. Parker, B. Borhan, S. Landt, A.D. Jones, B.D. Hammock, Molecular and biochemical evidence for the involvement of the Asp-333-His-523 pair in the catalytic mechanism of soluble epoxide hydrolase, J. Biol. Chem. 270 (1995) $7968-7974$.

[68] B. Borhan, A.D. Jones, F. Pinot, D.F. Grant, M.J. Kurth, B.D. Hammock, Mechanism of soluble epoxide hydrolase. Formation of an alpha-hydroxy ester-enzyme intermediate through Asp-333, J. Biol. Chem. 270 (1995) 26923-26930.

[69] M. Arand, H. Wagner, F. Oesch, Asp ${ }^{333}, \mathrm{Asp}^{495}$, and $\mathrm{His}^{523}$ form the catalytic triad of rat soluble epoxide hydrolase, J. Biol. Chem. 271 (1996) 4223-4229.

[70] M.A. Argiriadi, C. Morisseau, B.D. Hammode, D.W. Christianson, Detoxification of environmental mutagens and carcinogens: structure, mechanism and evolution of liver epoxide hydrolase, Proc. Natl. Acad. Sci. USA 96 (1999) 10637-10642.

[71] M. Shou, F.J. Gonzalez, H.V. Gelboin, Stereoselective epoxidation and hydration at the K-region of polycyclic aromatic hydrocarbons by cDNA-expressed cytochromes P450 1A1, 1A2, and epoxide hydrolase, Biochemistry 35 (1996) 15807-15813.

[72] F.P. Guengerich, Epoxide hydrolase: properties and metabolic roles, Rev. Biochem. Toxicol. 4 (1982) 5-30.

[73] R.N. Armstrong, Enzyme-catalyzed detoxication reactions: mechanisms and stereochemistry, CRC Crit. Rev. Biochem. 22 (1987) 39-88.

[74] C.J. Omiecinski, L. Aicher, R. Holubkov, H. Checkoway, Human peripheral lymphocytes as indicators of microsomal epoxide hydrolase activity in liver and lung, Pharmacogenetics 3 (1993) 150-158.

[75] D. Papadopoulos, H. Jornvall, J. Rydstrom, J.W. DePierre, Purification and initial characterization of microsomal epoxide hydrolase from the human adrenal gland, Biochim. Biophys. Acta 1206 (1994) 253-262.

[76] C. Hassett, S.M. Turnblom, A. DeAngeles, C.J. Omiecinski, Rabbit microsomal epoxide hydrolase: isolation and characterization of the xenobiotic metabolizing enzyme cDNA, Arch. Biochem. Biophys. 271 (1989) 380-389.

[77] R.C. Skoda, A. Demierre, O.W. McBride, F.J. Gonzalez, U.A. Meyer, Human microsomal xenobiotic epoxide hydrolase. Complementary DNA sequence, complementary DNA-directed expression in COS-1 cells, and chromosomal localization, J. Biol. Chem. 263 (1988) 1549-1554.

[78] N.J. Bulleid, A.B. Graham, J.A. Craft, Microsomal epoxide hydrolase of rat liver. Purification and characterization of enzyme fractions with different chromatographic characteristics, Biochem. J. 233 (1986) 607-611. 
[79] C. Hassett, K.B. Robinson, N.B. Beck, C.J. Omiecinski, The human microsomal epoxide hydrolase gene (EPHX1): complete nucleotide sequence and structural characterization, Genomics 23 (1994) 433-442.

[80] N.M. Wilson, C.J. Omiecinski, Xenobiotic microsomal epoxide hydrolase: $5^{\prime}$ sequence of the human gene, Biochim. Biophys. Acta 1008 (1989) 357-358.

[81] C. Hassett, E.M. Laurenzana, J.S. Sidhu, C.J. Omiecinski, Effects of chemical inducers on human microsomal epoxide hydrolase in primary hepatocyte cultures, Biochem. Pharmacol. 55 (1998) 1059-1069.

[82] A. Astrom, S. Man'er, J.W. DePierre, Induction of liver microsomal epoxide hydrolase, UDP-glucuronyl transferase and cytosolic glutathione transferase in different rodent species by 2-acetylaminofluorene or 3-methylcholanthrene, Xenobiotica 17 (1987) 155-163.

[83] M.K. Cho, S.G. Kim, Differential induction of rat hepatic microsomal epoxide hydrolase and rGSTA2 by diazines: the role of cytochrome P450 2E1-mediated metabolic activation, Chem. Biol. Interact. 116 (1998) 229-245.

[84] J.A. Craft, N.J. Bulleid, M.R. Jackson, B. Burchell, Induction of microsomal epoxide hydrolase by nitrosamines in rat liver. Effect on messenger ribonucleic acids, Biochem. Pharmacol. 37 (1988) 297-302.

[85] A. Parkinson, P.E. Thomas, D.E. Ryan, W. Levin, T. Fujita, S. Safe, Induction of rat liver microsomal cytochrome P-450 isozymes and epoxide hydrolase by a series of 4 '-substituted-2,3,4,5tetrachlorobiphenyls, Toxicology 53 (1988) 289-300.

[86] P.A. Bell, C.N. Falany, P. McQuiddy, C.B. Kasper, Glucocorticoid repression and basal regulation of the epoxide hydrolase promoter, Arch. Biochem. Biophys. 279 (1990) 363-369.

[87] A. Gaedigk, S.P. Spielberg, D.M. Grant, Characterization of the microsomal epoxide hydrolase gene in patients with anticonvulsant adverse drug reactions, Pharmacogenetics 4 (1994) 142-153.

[88] C. Hassett, L. Aicher, J.S. Sidhu, C.J. Omiecinski, Human microsomal epoxide hydrolase: genetic polymorphism and functional expression in vitro of amino acid variants, Hum. Mol. Genet. 3 (1994) 421-428.

[89] E.M. Laurenzana, C. Hassett, C.J. Omiecinski, Post-transcriptional regulation of human microsomal epoxide hydrolase, Pharmacogenetics 8 (1998) 157-167.

[90] C. Hassett, J. Lin, C.L. Carty, E.M. Laurenzana, C.J. Omiecinski, Human hepatic microsomal epoxide hydrolase: comparative analysis of polymorphic expression, Arch. Biochem. Biophys. 337 (1997) 275-283.

[91] S. Raaka, C. Hassett, C.J. Omiencinski, Human microsomal epoxide hydrolase: 5'-flanking region genetic polymorphisms, Carcinogenesis 19 (1998) 387-393.

[92] M.W. Himmelstein, M.J. Turner, B. Asgharian, J.A. Bond, Comparison of blood concentrations of 1,3-butadiene and butadiene epoxides in mice and rats exposed to 1,3-butadiene by inhalation, Carcinogenesis 15 (1994) 1479-1486.

[93] R.J. Krause, A.A. Elfarra, Oxidation of butadiene monoxide to meso- and ( + / - )-diepoxybutane by cDNA-expressed human cytochrome P450s and by mouse, rat, and human liver microsomes: evidence for preferential hydration of meso-diepoxybutane in rat and human liver microsomes, Arch. Biochem. Biophys. 337 (1997) 176-184.

[94] R.J. Krause, J.E. Sharer, A.A. Elfarra, Epoxide hydrolase-dependent metabolism of butadiene monoxide to 3-butene-1,2-diol in mouse, rat, and human liver, Drug Metab. Dispos. 25 (1997) $1013-1015$.

[95] R. Snyder, T. Chepiga, C.S. Yang, H. Thomas, K. Platt, F. Oesch, Benzene metabolism by reconstituted cytochromes $\mathrm{P} 4502 \mathrm{~B} 1$ and $2 \mathrm{E} 1$ and its modulation by cytochrome b5, microsomal epoxide hydrolase, and glutathione transferases: evidence for an important role of microsomal epoxide hydrolase in the formation of hydroquinone, Toxicol. Appl. Pharmacol. 122 (1993) $172-181$.

[96] A.B. Lindstrom, K. Yeowell-O’Connell, S. Waidyanatha, B.T. Golding, V.R. Tornero, S.M. Rappaport, Measurement of benzene oxide in the blood of rats following administration of benzene, Carcinogenesis 18 (1997) 1637-1641.

[97] F.P. Guengerich, W.W. Johnson, T. Shimada, Y.F. Ueng, H. Yamazaki, S. Langouet, Activation and detoxication of aflatoxin B1, Mutat. Res. 402 (1998) 121-128. 
[98] F.P. Guengerich, W.W. Johnson, Kinetics of hydrolysis and reaction of aflatoxin B1 exo-8,9-epoxide and relevance to toxicity and detoxication, Drug Metab. Rev. 31 (1999) 141-158.

[99] J.M. Walters, R.D. Combes, Activation of benzo[a]pyrene and aflatoxin B1 to mutagenic chemical species by microsomal preparations from rat liver and small intestine in relation to microsomal epoxide hydrolase, Mutagenesis 1 (1986) 45-48.

[100] H. Glatt, C. Wameling, S. Elsberg, H. Thomas, H. Marquardt, A. Hewer, D.H. Phillips, F. Oesch, A. Seidel, Genotoxicity characteristics of reverse diol-epoxides of chrysene, Carcinogenesis 14 (1993) $11-19$.

[101] S.K. Yang, Z.P. Bao, Stereoselective formations of K-region and non-K-region epoxides in the metabolism of chrysene by rat liver microsomal cytochrome P-450 isozymes, Mol. Pharmacol. 32 (1987) $73-80$.

[102] R.H. Heflich, J.R. Thornton Manning, T. Kinouchi, F.A. Beland, Mutagenicity of oxidized microsomal metabolites of 1-nitropyrene in Chinese hamster ovary cells, Mutagenesis 5 (1990) 151-157.

[103] P.J. van Bladeren, J.M. Sayer, D.E. Ryan, P.E. Thomas, W. Levin, D.M. Jerina, Differential stereoselectivity of cytochromes P-450b and P-450c in the formation of naphthalene and anthracene 1,2-oxides. The role of epoxide hydrolase in determining the enantiomer composition of the 1,2-dihydrodiols formed, J. Biol. Chem. 260 (1985) 10226-10235.

[104] M. Hall, D.K. Parker, A.J. Hewer, D.H. Phillips, P.L. Grover, Further metabolism of diol-epoxides of chrysene and dibenz[a,c]anthracene to DNA binding species as evidenced by ${ }^{32} \mathrm{P}$-postlabelling analysis, Carcinogenesis 9 (1988) 865-868.

[105] M. Miyata, G. Kudo, Y.H. Lee, T.J. Yang, H.V. Gelboin, P. Fernandez-Salguero, S. Kimura, F.J. Gonzalez, Targeted disruption of the microsomal epoxide hydrolase gene. Microsomal epoxide hydrolase is required for the carcinogenic activity of 7,12-dimethylbenz[a]anthracene, J. Biol. Chem. 274 (1999) 23963-23968.

[106] G. Bellucci, C. Chiappe, G. Ingrosso, Kinetics and stereochemistry of the microsomal epoxide hydrolase-catalyzed hydrolysis of cis-stilbene oxides, Chirality 6 (1994) 577-582.

[107] N.R. Kitteringham, C. Davis, N. Howard, M. Pirmohamed, B.K. Park, Interindividual and interspecies variation in hepatic microsomal epoxide hydrolase activity: studies with cis-stilbene oxide, carbamazepine 10, 11-epoxide and naphthalene, J. Pharmacol. Exp. Ther. 278 (1996) $1018-1027$.

[108] D.E. Moody, B.D. Hammock, Purification of microsomal epoxide hydrolase from liver of rhesus monkey: partial separation of cis- and trans-stilbene oxide hydrolase, Arch. Biochem. Biophys. 258 (1987) 156-166.

[109] G.P. Carlson, Metabolism of styrene oxide to styrene glycol by mouse liver and lung, J. Toxicol. Environ. Health 53 (1998) 19-27.

[110] M.G. Gadberry, D.B. DeNicola, G.P. Carlson, Pneumotoxicity and hepatotoxicity of styrene and styrene oxide, J. Toxicol. Environ. Health 48 (1996) 273-294.

[111] M.E. Herrero, M. Arand, J.G. Hengstler, F. Oesch, Recombinant expression of human microsomal epoxide hydrolase protects V79 Chinese hamster cells from styrene oxide- but not from ethylene oxide-induced DNA strand breaks, Environ. Mol. Mutagen. 30 (1997) 429-439.

[112] J.K. Hartsfield, Jr, L.B. Holmes, J.G. Morel, Phenytoin embryopathy: effect of epoxide hydrolase inhibitor on phenytoin exposure in utero in C57BL/6J mice, Biochem. Mol. Med. 56 (1995) $131-143$.

[113] R.J. Riley, J.L. Maggs, C. Lambert, N.R. Kitteringham, B.K. Park, An in vitro study of the microsomal metabolism and cellular toxicity of phenytoin, sorbinil and mianserin, Br. J. Clin. Pharmacol. 26 (1988) 577-588.

[114] D.C. Van Dyke, M.J. Berg, C.H. Olson, Differences in phenytoin biotransformation and susceptibility to congenital malformations: a review, DICP 25 (1991) 987-992.

[115] G. Bellucci, G. Berti, C. Chiappe, A. Lippi, F. Marioni, The metabolism of carbamazepine in humans: steric course of the enzymatic hydrolysis of the 10,11-epoxide, J. Med. Chem. 30 (1987) 768-773.

[116] H.P. Eugster, C. Sengstag, A. Hinnen, U.A. Meyer, F.E. Wurgler, Heterologous expression of human microsomal epoxide hydrolase in Saccharomyces cerevisiae. Study of the valpromide-carbamazepine epoxide interaction, Biochem. Pharmacol. 42 (1991) 1367-1372. 
[117] B.U. Vogel, P. Bentley, F. Oesch, Endogenous role of microsomal epoxide hydrolase. Ontogenesis, induction inhibition, tissue distribution, immunological behaviour and purification of microsomal epoxide hydrolase with $16 \alpha, 17 \alpha$-epoxyandrostene-3-one as substrate, Eur. J. Biochem. 126 (1982) 425-431.

[118] D. Papadopoulos, J. Seidegard, A. Georgellis, J. Rydstrom, Subcellular distribution, catalytic properties and partial purification of epoxide hydrolase in the human adrenal gland, Chem. Biol. Interact. 55 (1985) 249-260.

[119] G.D. Prestwich, I. Lucarelli, S.K. Park, D.N. Loury, D.E. Moody, B.D. Hammock, Cyclopropyl oxiranes: reversible inhibitors of cytosolic and microsomal epoxide hydrolases, Arch. Biochem. Biophys. 237 (1985) 361-372.

[120] J.S. Leeder, R.J. Riley, V.A. Cook, S.P. Spielberg, Human anti-cytochrome P450 antibodies in aromatic anticonvulsant-induced hypersensitivity reactions, J. Pharmacol. Exp. Ther. 263 (1992) $360-367$.

[121] N.H. Shear, S.P. Spielberg, Anticonvulsant hypersensitivity syndrome. In vitro assessment of risk, J. Clin. Invest. 82 (1988) 1826-1832.

[122] V.J. Green, M. Pirmohamed, N.R. Kitteringham, A. Gaedigk, D.M. Grant, M. Boxer, B. Burchell, B.K. Park, Genetic analysis of microsomal epoxide hydrolase in patients with carbamazepine hypersensitivity, Biochem. Pharmacol. 50 (1995) 1353-1359.

[123] J.S. Leeder, A. Gaedigk, X. Lu, V.A. Cook, Epitope mapping studies with human anti-cytochrome P450 3A antibodies, Mol. Pharmacol. 49 (1996) 234-243.

[124] S. Benhamou, M. Reinikainen, C. Bouchardy, P. Dayer, A. Hirvonen, Association between lung cancer and microsomal epoxide hydrolase genotypes, Cancer Res. 58 (1998) 5291-5293.

[125] J.E. Hulla, M.S. Miller, J.A. Taylor, D.W. Hein, C.E. Furlong, C.J. Omiecinski, T.A. Kunkel, Symposium overview: the role of genetic polymorphism and repair deficiencies in environmental disease, Toxicol. Sci. 47 (1999) 135-143.

[126] P. Lin, S.L. Wang, H.J. Wang, K.W. Chen, H.S. Lee, K.J. Tsai, C.Y. Chen, H. Lee, Association of CYP1A1 and microsomal epoxide hydrolase polymorphisms with lung squamous cell carcinoma, Br. J. Cancer 82 (2000) 852-857.

[127] D.J. Harrison, A.L. Hubbard, J. MacMillan, A.H. Wyllie, C.A. Smith, Microsomal epoxide hydrolase gene polymorphism and susceptibility to colon cancer, Br. J. Cancer 79 (1999) 168-171.

[128] J.G. Hengstler, M. Arand, M.E. Herrero, F. Oesch, Polymorphisms of $N$-acetyltransferases, glutathione $S$-transferases, microsomal epoxide hydrolase and sulfotransferases: influence on cancer susceptibility, Recent Results Cancer Res. 154 (1998) 47-85.

[129] L.T. Laughlin, H.F. Tzeng, S. Lin, R.N. Armstrong, Mechanism of microsomal epoxide hydrolase, semifunctional site-specific mutants affecting the alkylation half-reaction, Biochemistry 37 (1998) 2897-2904.

[130] M. Arand, F. Muller, A. Mecky, W. Hinz, P. Urban, D. Pompon, R. Kellner, F. Oesch, Catalytic triad of microsomal epoxide hydrolase: replacement of Glu404 with Asp leads to a strongly increased turnover rate, Biochem. J. 337 (1999) 37-43.

[131] P.A. Bell, C.B. Kasper, Expression of rat microsomal epoxide hydrolase in Escherichia coli. Identification of a histidyl residue essential for catalysis, J. Biol. Chem. 268 (1993) 14011-14017.

[132] G.M. Lacourciere, R.N. Armstrong, Microsomal and soluble epoxide hydrolases are members of the same family of C-X bond hydrolase enzymes, Chem. Res. Toxicol. 7 (1994) 121-124.

[133] M. Arand, H. Hemmer, H. Durk, J. Baratti, A. Archelas, R. Furstoss, F. Oesch, Cloning and molecular characterization of a soluble epoxide hydrolase from Aspergillus niger that is related to mammalian microsomal epoxide hydrolase, Biochem. J. 344 (1999) 273-280.

[134] J. Zou, B.M. Hallberg, T. Bergfors, F. Oesch, M. Arand, S.L. Mowbray, T.A. Jones, Structure of Aspergillus niger epoxide hydrolase at 1.8 A resolution: implications for the structure and function of the mammalian microsomal class of epoxide hydrolases. Structure, Fold Des. 8 (2000) 111-122. 